NOTAS

\title{
ENTRE MITO Y REALIDAD
}

Carlos de la Isla*

Alberto Sauret Botteri escribió un libro excelente sobre la 'permanencia del mito’. Yo me siento muy honrado con la invitación para hacer un comentario. Esto no es una presentación ni menos una reseña, porque hablando del mito, el libro mismo toma cuerpo de mito en el sentido de ejemplaridad, de cierta infinitud y misterio, de una inabarcable expresión de tiempo y de significado.

Es tal la densidad y riqueza conceptuales del contenido que cualquier descripción sería imperdonablemente pobre y distorsionante. Por eso, más que una presentación quiero hacer una invitación para leer este libro. Así que "nada crean de lo que yo diga”, como decía Karl Popper a sus oyentes (citado por Sauret). Lean, sin embargo con atención y avidez Permanencia del mito.

* Departamento Académico de Estudios Generales, ITAM.
Haré unas cuantas reflexiones arbitrarias, inspiradas más en razones sensitivas que por algún ordenamiento lógico. Y creo que este camino es legítimo ya que sería inaceptable intentar un análisis lógico de los mitos expresados, que en tantas dimensiones escapan a la razón, la que con frecuencia se convierte en mito. Porque como dice Cassirer de la unidad de la conciencia mítica y de la conciencia cognoscitiva pura, que antes de alcanzar su configuración y su sello lógico determinados debieron haber pasado por un estadio mitológico.

El hombre por su propia hechura es un constructor de mitos. Fue llamado homo sapiens más por su potencia de saber que por su sabiduría. De hecho su sapiencia ha sido, sigue siendo tan reducida que sus explicaciones del mundo y de sí mismo son proyecciones de sus carencias y de sus pretensiones ilimitadas. Así 
aparecen los primeros ídolos, los prometeos que se proponen romper sus cadenas. Así, el hombre de todos los tiempos, crea sus dioses revestidos de grandeza y de caprichosa belleza, pero del tamaño de sus pasiones y de sus sueños; crea también sus instituciones a su servicio, sus ideas, su ciencia, su técnica, sus razones, sus historias. A todos sus ídolos les atribuye cualidades que él añora: poder, infinito poder, sabiduría, dominio, y de esta manera genera el mito de sí mismo.

El paso siguiente, largo paso de milenios, ha sido la historia del sometimiento del hombre a sus propios ídolos como si poseyeran el tamaño y los poderes que les ha atribuido.

Resultado: un hombre sometido a sus propias creaciones, sometido no sólo a lo acontecido in illo tempore, $a b$ initio, en expresión de Eliade, sino a lo que sucede aquí y ahora en un mito que determina la historia y que es lo que parece interesar más a Sauret Botteri, quien en la parte del mito y la conciencia histórica toma la siguiente expresión de Cassirer: "En la relación de mito e historia es aquél siempre lo primario y ésta lo secundario y derivado. No es la historia de un pueblo la que determina su mitología, sino al revés, es su mitología la que determina su historia; o más bien, no determina, sino que ella misma es su destino, la suerte que le toca desde el comienzo.”

Y en este mismo contexto aparece la expresión de Paul Valéry: “Toda la historia está hecha únicamente de pensamientos modelados por ese valor esencialmente mítico de representar lo que fue. Mito es el nombre de todo lo que no existe y solamente subsiste teniendo la palabra por motivo. Hay en nosotros tantos mitos y tan familiares que es casi imposible separar claramente de nuestra mente algo que no lo sea. Ni siquiera podemos hablar sin continuar mitificando. Mañana es un mito.”

Con esta percepción la idea, de Bloch de la historia como "ciencia de los hombres” en el tiempo debe ser reconstruida desde los datos míticos del hombre como historia, desde la historia-mito en relación consubstancial y desde un tiempo que es el relator de tal substancia.

Como dice Pieper (citado por Sauret): “Comienzo y fin de la historia sólo son concebibles desde una interpretación mítica, revelada o inventada."

Puesta aparte la discusión sobre el determinismo histórico o sobre el mito determinante de la historia, lo que resulta inobjetable es la importancia del poder del mito y del mito del poder, y en este excelente libro encontraron estancia los mitos del progreso, de la ciencia, de la socie- 
NOTAS

dad científica, de la economía y la política, de la escatología y del milenarismo, de la conciencia histórica, de la modernidad y de la postmodernidad.

Y debo decir que la estancia que Alberto Sauret ha construido para el mito es una estancia amplia y profunda, elegante y luminosa, de una inmensa temporalidad sin tiempos y de una infinita espacialidad sin concreción de espacios. Por eso, como sugiero al principio, la 'permanencia del mito', ella misma, termina convertida en mito en el sentido más digno y elevado de la palabra mito o en la expresión mejor del mito de la palabra.

Con sobrada razón Alberto Sauret inicia el despliegue, el desatamiento del mito en la "genealogía de la idea de progreso, mito cosmogónico de la modernidad". Pone un interés preocupado y cuidadoso en el análisis o disección del mito del Progreso; muestra la génesis, evolución, consistencia, persistencia y fuerza motriz de este poderoso mito que ha impuesto su esencia y su substancia, no sólo en la historia de la humanidad, sino también en todos los demás mitos que configuran la historia: En palabras del autor: "La substancia proteica de los mitos subyace en estratos medio sumergidos de la conciencia como difusas categorías ontológicas que condicionan nuestra percepción y predisponen para la acción" y antes: "El mito del progreso, en el que me interesa detenerme, no es una creación ex nihilo, sino que resulta tributario de antiguas y prolongadas creencias que han permanecido como bajo profundo desde sus remotos orígenes, y que han aflorado con variadas apariencias en diversas circunstancias." "En primer lugar -dice Sauret- me interesa exhibir hitos de esta trayectoria, en segundo, mostrar cómo los mitos no desaparecen súbitamente por la conjura de una determinación intelectual, sino que, al igual que los antiguos dioses, no mueren sino que se asimilan, sincretizan, metamorfosean con las nuevas divinidades triunfadoras." $Y$ en ese cuidadoso análisis del mito del Progreso Sauret también encontró el progreso inscrito en las paredes tiznadas y en los bosques de chimeneas que se avergonzaron de las abultadas bocanadas de humo como nubes de tormenta amenazante y se ocultaron hipócritamente debajo de los automotores, convertidos en muchos miles de millones de escapes productores de un veneno invisible.

En el análisis aparece el tiempo pacífico, medidor de un movimiento casi imperceptible, que dejaba el libre recorrido de la vida casi sin medida; ese tiempo acaparado por el progreso y convertido en precio pre- 
cioso de mercado y en la tiranía despiadada de las manecillas.

Los hombres y mujeres, los niños y los ancianos que vivían y convivían lentamente con la naturaleza las salidas y las puestas del sol, jugando y trabajando, corriendo y amando, todos ellos también fueron sometidos por el progreso y uncidos a las cadenas de las máquinas. Ese progreso inventó la explotación para la acumulación y la riqueza producida por la indigencia de las mayorías y por la conversión de las personas en medios de producción.

Ese progreso transformó el sentido maravilloso de la vida, la vivencia natural de la naturaleza, destrozó la arquitectura original e ilusionada de los proyectos personales y los convirtió en productos en serie cuadrados y chatos de acuerdo a la mercadotecnia, por las leyes imperativas del mercado.

Este progreso cabalga frenéticamente en un potro brioso, en el mejor corcel, hijo del relámpago, hacia Samarra al encuentro con la muerte, encauzada por tres orientaciones aberrantes e imbricadas: la economía, la ecología y la energía; según la metáfora usada por Tiezzi, citado por Sauret, quien también aporta la afirmación de Heidegger: "Se está preparando, con los medios de la técnica, una agresión contra la vida y la esencia del ser humano, compa- rada con la cual bien poco significa la explosión de la bomba de hidrógeno."

El mito lo permea todo, impone el rubro y exigencia de su dominio. La persona es manejada con sutileza imperceptible y convertida en instrumento del éxito del mercado, de la economía, de la modernidad.

Por eso, sin respeto alguno a los cánones tradicionales ni al ámbito de la sacralidad, "modernidad y moda no tienen un lazo sólo terminológico", dice Vattimo. "La secularización entendida como lo moderno es un término que describe el valor que domina y guía la conciencia de la época en cuestión, sobre todo como fe en el progreso (que es una fe secularizada y al propio tiempo una fe en la secularización). Pero cabalmente la fe en el progreso, entendida como fe en el proceso histórico y cada vez más despojada de referencias providenciales y metahistóricas se identifica pura y simplemente con la fe en el valor de lo nuevo."

Alberto Sauret subraya con énfasis especial el mito del consumo. "El consumo, dice, es un mito porque es la palabra con que la sociedad contemporánea se nombra, se piensa y se vive a sí misma." Y cita a Baudrillard: en esa expresión que muestra la obsesión de la idea de consumo: "la única realidad objetiva del consumo es la idea de consumo”. En la misma 
NOTAS

medida en que consume se consume a sí misma como sociedad de consumo en cuanto idea, y la publicidad es el himno triunfal de esta idea, es la dimensión fundamental. "La abundancia y el consumo no de bienes materiales, sino de la imagen consumida del consumo constituyen la nueva mitología de nuestra tribu, la moral de nuestra modernidad."

En todos los ámbitos del mito aparece el hombre sometido, aunque sus pretensiones son de endiosamiento: sin embargo Sauret no sustenta la postura fatalista. Así, afirma en el capítulo de mito, modernidad y postmodernidad: "Aunque el optimismo no nos dé abasto para seguir creyendo con Sartre que el hombre está condenado a la libertad, me parece que todavía podemos creer también con él que el ser hombre implica estar dotado de ciertos límites para resistir el embrutecimiento y la enajenación forzada.” Y su fe en este poder de resistencia impulsa a Sauret a dedicar este libro a esa mujer maravillosa que es, y me consta, principio de certidumbre. La dedicatoria una, breve, densa dice: "A Pirota de Victoria, principio de certidumbre.”

Para cerrar este comentario permítanme una interpretación psicoanalítica sobre la hechura de este libro: Me he preguntado cómo Alberto Sauret logró escribir una obra tan valiosa, exacta y profunda sobre el mito, y me parece que la respuesta está en su inconsciente. Creo que en el inconsciente de Alberto Sauret se debate una fuerte tensión entre mito y realidad, entre sublimación y realismo, entre el logro destructor y el modelo ejemplar, entre la utopía esperanzadora y la obscuridad del presente, entre pulsiones estéticas y pulsiones místicas.

Esta hipótesis la confirmo por la pasión de Alberto Sauret por representar en el teatro, con éxito premiado, a personajes míticos; siendo sus preferidos la pareja dialéctica del todopoderoso Júpiter Tonante y del alegre Baco.

De la fuerte lucha de estas múltiples y apretadas tensiones ha nacido este excelente libro, pero principalmente el agudísimo sentido del humor, la calidad crítica inexorable, la inmensa capacidad para gozar y tomar la vida en serio, la inquebrantable fidelidad en la amistad... En una palabra, de estas fuerzas del inconsciente combinadas con su lúcida conciencia ha nacido y crecido la singuralísima personalidad de Alberto Sauret Botteri. 